\title{
Comparison of effectiveness of mifepristone misoprostol combination versus mifepristone Foley EAS (Extra-amniotic instillation of saline) combination in second trimester pregnancy termination
}

\author{
Kusumam V.N., ${ }^{1, *}$ Naseema Beevi Ahamad Khan ${ }^{2}$, Sruthi. V.G ${ }^{3}$ \\ 1,2 Additional Professor, ${ }^{3}$ Junior Resident, Dept. of Obstetrics and Gynaecology, Government Medical College, Kozhikode, \\ Kerala, India
}

*Corresponding Author: Kusumam V.N

Email: vnkusumam1234@gmail.com

Received: $29^{\text {th }}$ August, 2018

Accepted: $13^{\text {th }}$ October, 2018

\begin{abstract}
Second trimester medical abortion with mifepristone followed by misoprostol is effective and is associated with considerably shorter induction abortion interval. This study is a comparison of the effectiveness, safety profile and side effects of mifepristonemisoprostol and mifepristone-Foley's EAS combinations in second trimester termination. The patients were grouped into two, first group received oral mifepristone $200 \mathrm{mg}$ followed by vaginal misoprostol $800 \mathrm{mcg}$ after 48 hours and then $400 \mathrm{mcg}$ misoprostol vaginally 3 hourly up to a maximum of 4 further doses. Second group were induced with oral mifepristone $200 \mathrm{mg}$ followed by extra amniotic saline instillation through a Foley's catheter after 48 hours. The success rates were comparable between the two groups. But the 6 hour expulsion rates $(36.4 \% \mathrm{Vs} 0 \%)$ as well as 12 hour expulsion rates $(56.36 \% \mathrm{Vs} 3.6 \%)(\mathrm{p}$ value $=0.001$ ) were significantly high in mifepristone - misoprostol group compared to mifepristone-Foley EAS group. Mean induction abortion interval was shorter in the first group (14.64hrs vs $18.4 \mathrm{hrs})(\mathrm{p}=0.026)$. But the incidence of complaints after administration of misoprostol was significantly high. 7 patients from Group 1 and 5 patients from Group 2 required surgical evacuation for retained placenta. The study revealed that mifepristone-Foley's EAS induction can be used as an effective alternative to mifepristone-misoprostol combination with similar success rates and significantly reduced side effects but with significantly increased induction abortion interval. The results of this study can be extrapolated to cases where prostaglandins are contraindicated like in previous cesarean section cases.
\end{abstract}

Keywords: Foley EAS, Misoprostol, Abortion, Mifepristone.

\section{Introduction}

Among unintended 205 million pregnancies that occur each year worldwide, about $20 \%$ of them end in induced abortion. Majority of these abortions occur during the first trimester of pregnancy. The second trimester of pregnancy is subdivided into an early period between 13-20 weeks and a late period between 20-28 weeks. Advanced screening techniques have led to an increase in the detection of congenital malformations with subsequent gradual increase in second trimester termination of pregnancy which represents $10-15 \%$ of total abortions performed worldwide. ${ }^{1}$

Termination in the second trimester is more risky than during first trimester. ${ }^{2}$ So the pharmacologic management seems to be an appealing alternative to surgical evacuation. misoprostol has been widely used in different dosage and routes for second trimester pregnancy terminations. Second trimester medical abortion with mifepristone followed by misoprostol is effective and is associated with considerably shorter induction to abortion interval. ${ }^{3} \mathrm{~A}$ recent systemic review concluded that osmotic dilators were superior to prostaglandins. ${ }^{4}$ Several studies have described that extra-amniotic instillation of saline by Foley's catheter helps in ripening the cervix. ${ }^{5}$

This study is designed to investigate whether insertion of a fluid filled trans-cervical Foley's catheter after an oral mifepristone of $200 \mathrm{mg}$ is better than mifepristone followed by vaginal misoprostol in terminating second trimester pregnancies. ${ }^{6,7}$

\section{Materials and Methods}

Study Design: Prospective comparative study.

Study Setting and Period: This study was conducted at the Institute of Maternal and child health, Govt. Medical College, Kozhikode.

Period: Jan-Dec 2016

Inclusion Criteria: Women 18 years and older with singleton pregnancy who needed to have termination of pregnancy in second trimester between $14-20$ weeks either on request or due to fetal anomaly. ${ }^{8}$ Gestational age was calculated from the date of first day of last menstrual period and dated by ultrasound scan.

Exclusion Criteria: Women with any of the following will be excluded from the study.

1. Previous uterine scar

2. Hypersensitivity to misoprostol

3. Hypersensitivity to mifepristone.

4. Haemoglobin less than $9 \mathrm{~g} / \mathrm{dl}$.

5. Severe or recurrent liver disease

6. Abnormal liver or renal function test

7. History of or evidence of thromboembolism

8. Low lying placenta

9. Surgery to the cevix

10. Chorioamnionitis 
11. Previable preterm premature rupture of membrane.

These were eliminated by interrogating the patient and from case history.

Sample Size: As per reference number 4, from the study conducted by Brown's et al to compare the different regimens of misoprostol for second trimester pregnancy termination, it was evident that complete expulsion of foetus and placenta occurred only in $73 \%$ cases with misoprostol 400 microgram at 4 hour intervals upto a maximum of 10 administrations. ${ }^{9,10}$ Expecting $20 \%$ change in expulsion rate, to get $5 \%$ significance level and $80 \%$ power for the test, the sample size required is

$\mathrm{n}=2(\mathrm{Z} \alpha+\mathrm{Z} \beta) 2 \mathrm{pq} / \mathrm{d} 2$

$\mathrm{p} 1=73 \%, \mathrm{p} 2=93 \%, \mathrm{p}=83 \%, \mathrm{q}=17 \%, \mathrm{~d}=20 \%$

$\mathrm{n}=2(1.96+0.84) 20.83 \times 0.17 / 0.04$

$\mathrm{n}=55$

So 55 pregnant women were recruited in each group.

Methodology: All the participants were subjected to complete history taking and thorough clinical examination and investigations. Written informed consent was obtained from all the participants. ${ }^{11}$ Group 1 participants were induced with oral mifepristone 200 $\mathrm{mg}$ in empty stomach followed by vaginal misoprostol 800 microgram kept in the posterior fornix of vagina after 48 hours and then 400 microgram misoprostol vaginally 3 hourly upto a maximum of 4 doses. ${ }^{12,3}$ The outcome of the study was measured at this point. If abortion did not occur even after 12 hours of the last dose of misoprostol, it was considered as failure of the method, but induction was continued by repeating the cycle. In group 2, induction was done by oral mifepristone $200 \mathrm{mg}$ in empty stomach followed by extra amniotic saline infusion through a Foley's catheter after 48 hours. Participants were asked to empty the bladder. Procedure was explained to the patient. With the patient in lithotomy, vulva and vagina were cleaned with Povidon Iodine and cervix was visualised using a sterile speculum. The anterior lip of cervix was grasped with a sponge holding forceps and another sponge holding forceps was used to push the catheter through the cervix under direct visualisation. The bulb was inflated with $50 \mathrm{ml}$ normal saline. $150 \mathrm{ml}$ of normal saline was infused extraamniotically. Gentle traction was applied to the catheter and the catheter was fixed to the inner aspect of thigh using adhesive plaster. The whole procedure was done under strict aseptic precautions, so prophylactic antibiotics was not given as per the institution policy. As soon as the catheter was expelled, reassessment of the dilatation and effacement of the cervix was carried out. If spontaneous expulsion of foetus did not occur even after 12 hours of expulsion of Foley's catheter or if the Foley's catheter was not expelled even after 24 hours of insertion, the method was taken as failure. In the second case, vaginal examination was done and catheter was deflated and removed. In both the above said situations of failure pervaginal examination was done and Bishop score was assessed. Induction was continued with Vaginal misoprostol as in the first group or with Oxytocin drip as per the Bishop score the patients were monitored every 4 th hours for vital signs, uterine contractions and occurrence of complications such as nausea, vomiting, abdominal pain, shivering, fever. Vaginal examination was done 48 hours after mifepristone, then before each dose of misoprostol and in group 2, as soon as the Foley's catheter was expelled or deflated and removed and 12hours after expulsion of Foley's catheter. All the patients received intravenous Oxytocin 20 IU after expulsion offoetus to help placental separation and delivery. Retained placenta was considered if no manifestation of placental separation after 30 minutes offoetal expulsion. Surgical evacuation was done in such cases.

The time of expulsion of foetus and placenta were recorded in both the groups. After the expulsion, the women were examined for uterine atony and excessive post abortal bleeding. ${ }^{13}$ Vaginal examination was done to ensure that the abortion was complete and to rule out any cervical injury. Weight of the foetus was measured and the placenta was examined for completeness. Surgical evacuation was done if any remnants of conception such as missed placental lobe or pieces of membrane was suspected in which case it was considered as failure. Complete blood count was done on the next day. So to conclude, if abortion did not occur 12 hours after the last dose of misoprostol in first group, or, 12 hours after the expulsion of foley or if the foleys catheter was not expelled 24 hours after insertion, patients were considered failure and reassessed.

Success Rate: The number of participants in whom complete abortion occurred within the prescribed time interval. ${ }^{14}$ Complete abortion means the expulsion of foetus and placenta completely through the cervical canal unaided. The completeness of expulsion was confirmed by per vaginal examination.

Additional Doses /Alternative Method Required: In the first group, the number of additional doses of misoprostol required for complete abortion after the method was declared failure, was recorded. ${ }^{15}$ In the second group, the need for alternative methods and their number required after Foley EAS induction for a successful outcome was noted.

\section{Results}

Total of 110 eligible subjects were recruited for the study who were all in their second trimester of pregnancy between 13-20 weeks, all of them consented for the study and were randomised into two groups, with 55 women located to the mifepristone misoprostol group and the other 55 allocated to the mifepristone foley EAS group. All the 110 subjects were analysed. A participant flow chart is shown in Fig. 1. 


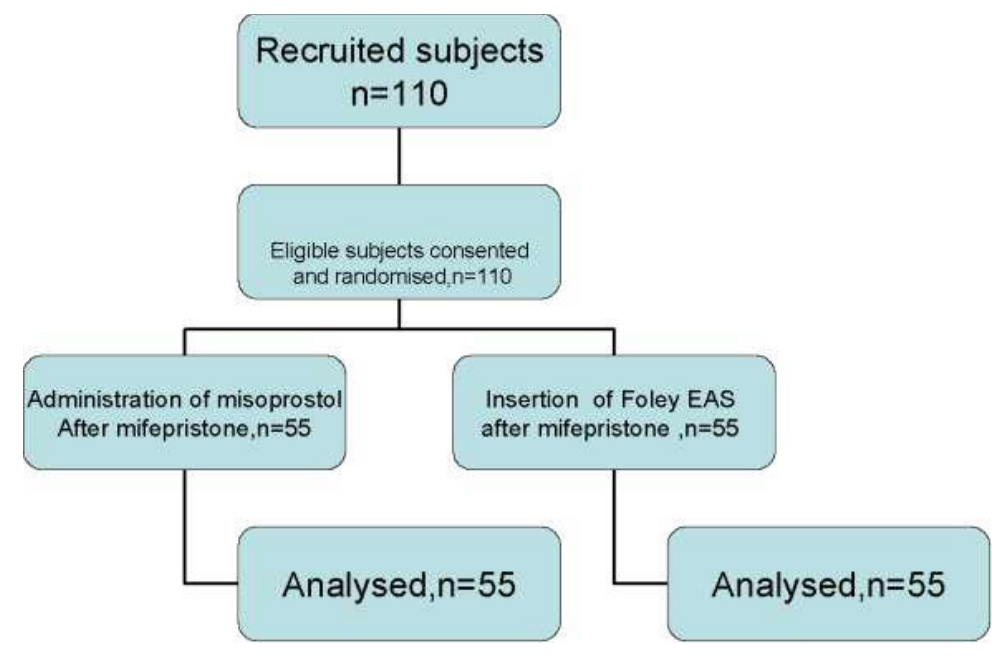

Fig. 1

The baseline demography of the two study groups were similar as presented in Table 1 .

Table 1: Baseline demograpics of the study population

\begin{tabular}{|l|c|c|c|}
\hline & $\begin{array}{c}\text { mifepristone misoprostol } \\
\text { group }(\mathbf{n = 5 5})\end{array}$ & $\begin{array}{c}\text { Mifepristone Foley EAS } \\
\text { group }(\mathbf{n}=\mathbf{5 5})\end{array}$ & P value \\
\hline Mean age (years) & 25.6 & 25.7 & $\mathrm{P}=0.84$ \\
\hline Mean height $(\mathrm{cm})$ & 159.91 & 160.25 & $\mathrm{P}=0.06$ \\
\hline Mean weight $(\mathrm{kg})$ & 58.36 & 58.64 & $\mathrm{P}=0.63$ \\
\hline Mean BMI & 22.79 & 22.84 & $\mathrm{P}=0.645$ \\
\hline Gravidity primi (number) & $24(43.6 \%)$ & $26(47.3 \%)$ & $\mathrm{P}=0.70$ \\
\hline Multi (number) & $31(56.4 \%)$ & $29(56.4 \%)$ & $\mathrm{P}=0.70$ \\
\hline Gestational age(by USG) & 18.65 & 18.67 & $\mathrm{P}=0.645$ \\
\hline
\end{tabular}

\section{Abortion Outcome}

The outcome of the abortion process are shown in Table 2

\section{Table 2: Abortion outcome}

\begin{tabular}{|l|c|c|c|}
\hline \multicolumn{1}{|c|}{ Outcome variables } & Group 1 $(\mathbf{n}=\mathbf{5 5})$ & Group 2 $(\mathbf{n}=\mathbf{5 5})$ & P Value \\
\hline 1. success rate & $43(78.3 \%)$ & $42(76.4 \%)$ & 0.82 \\
\hline 2. 6 hour expulsion rate & $20(36.4 \%)$ & 0 & .001 \\
\hline 3. 6-12 hour expulsion rate & $11(20 \%)$ & $2(3.6 \%)$ & .001 \\
\hline 4. Failure & $12(21.8 \%)$ & $13(23.6 \%)$ & .82 \\
\hline 5. Surgical evacuation & $7(12.7 \%)$ & $5(9.1 \%)$ & .7 \\
\hline 6. Induction abortion intervals (hours) & 14.64 & 18.4 & .02 \\
\hline 7. Mean Hb before abortion $(\mathrm{g} / \mathrm{dl})$ & 11.6 & 11.5 & .30 \\
\hline 8. Mean Hb after abortion $(\mathrm{g} / \mathrm{dl})$ & 11.41 & 11.32 & .25 \\
\hline
\end{tabular}

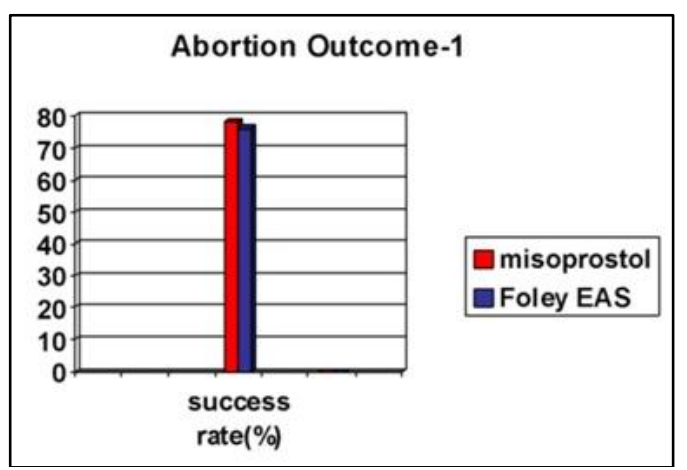

Fig. 2
The overall success rate was not significantly different between the 2 groups $(78.2 \%$ versus $76.4 \%$, $\mathrm{P}=0.82)$. However the 6 hour expulsion rate $(36.4 \%$ versus $0 \%, \mathrm{p}=0.001$ ) and 12 hour expulsion rate $(56.36 \%$ versus $3.6 \%, \mathrm{p}=0.001)$ were significantly higher in the mifepristone - misoprostol group. ${ }^{16}$ Not even a single women expelled within 6 hours in the mifepristone foley EAS group whereas 20 out of the 55 expelled within this time period in the mifepristonemisoprostol group. Similarly 31 women out of the 55 in the mifepristone-misoprostol group expelled within 12 hours whereas only 2 women out of the 55 in the 
second group expelled within this period. The failure rate $(21.8 \%$ versus $23.6 \%, \mathrm{p}=0.82)$ and the need for surgical evacuation $(12.7 \%$ versus $9.1 \%, \mathrm{p}=0.7)$ were also similar between the two groups. But the induction abortion interval was significantly shorter in the first group (14.64 hours versus 18.4 hours, $\mathrm{p}=0.02)$ compared to mifepristone foley EAS group. Difference in the haemoglobin level before and after abortion between the two groups were insignificant.

Side Effects: The incidence of side effects after the administration of the two methods is shown in table

Table 3

\begin{tabular}{|l|c|c|c|}
\hline & Group 1 (n=55) & Group 2 (n=55) & P Value \\
\hline 1. Nausea & $28(50.9 \%)$ & $3(5.5 \%)$ & 0.008 \\
\hline 2. Vomiting & $21(38.2 \%)$ & 0 & 0.001 \\
\hline 3. Headache & $9(16.4 \%)$ & $1(1.8 \%)$ & 0.008 \\
\hline 4. Fever & $23(41.8 \%)$ & $1(1.8 \%)$ & 0.001 \\
\hline 5. Shivering & $27(49.1 \%)$ & $2(3.6 \%)$ & 0.001 \\
\hline
\end{tabular}

The inclusion of prostaglandins in the management of pregnancy termination has changed the conventional way of surgical evacuation of uterus. ${ }^{17}$ Osmotic dilators like Foley EAS are promising alternative with a comparable efficacy in second trimester terminations especially in situations where prostaglandins are contraindicated as in previous cesarean cases.

Different studies have been conducted to compare the effectiveness and side effect profile of these two different methods. The study conducted by Ayman Shabana et al showed $100 \%$ expulsion rate with PGE1 alone and PGE1 Foley EAS combination as well, but with shorter induction abortion interval when foley EAS is used along with prostaglandins for termination (15.6 versus 21.9 hours), without significant difference in the occurrence of side effects. Early studies comparing the Foley catheter with PGE1 tablets found no difference in the termination time between the two methods. Sharmila Ijas Munir et al reported significantly higher rate of success $(82 \%)$ with misoprostol compared to Foley EAS (44\%) for second trimester pregnancy termination with no significant difference in the side effect profile.

In my study the success rate was comparable between the two groups $(78.2 \%$ versus $76.4 \%$, $\mathrm{p}=0.82) .{ }^{18}$ But the 6 hour expulsion rate $(36.4 \%$ versus $0 \%)$ as well as the 12 hour expulsion rate (56.36 versus $3.6 \%, \mathrm{p}=0.001$ ) were significantly high in the mifepristone misoprostol group compared to mifepristone Foley EAS group.

\section{Conclusion}

1. Foley EAS induction can be used as an effective alternative to misoprostol with similar success rate and significantly reduced side effects but with significantly increased $I-A$ interval.

2. The results of this study can be extrapolated to cases where prostaglandins are contraindicated like in previous cesarean cases and other similar situations.

\section{Reference}

1. ACOG Practice Bulletin No. 135: Second-trimester abortion. Obstet Gynecol. 2013;121(6):1394-406.

2. Fathalla MM, Maghraby AM, AL-Hussaini TK, Ismail AM. Different methods of termination of second trimester pregnancy at Women's Health Hospital, Assiut University: efficacy and complications. Int J Reprod Contracept Obstet Gynecol. 2017;6(8):3241-6.

3. Blum M. Experience with the induction of secondtrimester abortion by extra-amniotic physiological saline infusion. Report of 127 cases. Eur J Obstet Gynecol. 1980;10(3):183-5.

4. Brouns JFGM, van Wely M, Burger MPM, van Wijngaarden WJ. Comparison of two dose regimens of misoprostol for second-trimester pregnancy termination. Contraception. 2010;82(3):266-75.

5. Shabana A, Salah H, Kandil M, Soliman E, Morsi D. Termination of mid-trimester pregnancies: misoprostol versus concurrent weighted Foley catheter and misoprostol. F1000Research [Internet]. 2012 Nov 28 [cited 2018 Aug 16]; Available from: http://f1000research.com/articles/1-36/v2

6. Rezk MA-A, Sanad Z, Dawood R, Emarh M, Masood A. Comparison of intravaginal misoprostol and intracervical Foley catheter alone or in combination for termination of second trimester pregnancy. J Matern Fetal Neonatal Med. 2015;28(1):93-6.

7. Ranjan S, Sarojini A, Mohapatra I, Vivekanand A, Ranjan S. Comparison of intravaginal misoprostol alone and in combination with intracervical Foley's catheter for termination of second trimes- ter pregnancy- 3 years study at a tertiary care hospital. :6.

8. 3270 RCOG Abortion guideline.qxd. :145.

9. Dickinson JE, Evans SF. The optimization of intravaginal misoprostol dosing schedules in second-trimester pregnancy termination. Am J Obstet Gynecol. 2002;186(3):470-4.

10. Liu H-S, Yu M-H, Chang Y-K, Chu T-Y. Second and early third trimester pregnancy termination by extraamniotic balloon and intracervical PGE2. Int J Gynecol Obstet. 1998;60(1):29-34.

11. Kunwar S, Saha PK, Goel P, Huria A, Tandon R, Sehgal A. Second trimester pregnancy termination with $400 \mu \mathrm{g}$ vaginal misoprostol: efficacy and safety. Biosci Trends. 2010;4(6):351-4.

12. Munir Si, Ishtiaq S, Shafiq S, Javed L, Rana T. Mid Trimester Termination of Pregnancy in women with previous Caesarean Section: a comparison of Misoprostol, PGF2 $\alpha$ and Intra-Cervical Foley's Catheter Traction. :5. 
13. Toptas T, Mendilcioglu I, Simsek M, Taskin O. Intravaginal misoprostol alone versus intravaginal misoprostol and extraamniotic Foley catheter for second trimester pregnancy termination: an observational study. Ginekol Pol. 2014;85(8):577-81.

14. Abbas Mitwaly AB, Abbas AM, Abdellah MS. Intra uterine extra-amniotic versus vaginal misoprostol for termination of second trimester miscarriage: A randomized controlled trial. Int J Reprod Biomed. 2016;14(10):643-8.

15. Ercan Ö, Köstü B, Özer A, Serin S, Bakacak M. Misoprostol versus misoprostol and foley catheter combination in 2nd trimester pregnancy terminations. $J$ Matern Fetal Neonatal Med. 2016;29(17):2810-2.

16. Velipasaoglu M, Ozdemir CY, Ozek B, Ayaz R, Tanir HM. Sequential use of Foley catheter with misoprostol for second trimester pregnancy termination in women with and without caesarean scars: a prospective cohort study. J Matern Fetal Neonatal Med. 2018;31(5):677-81.

17. Halimi S, Halimi SMA, Shoaib M. Termination of Second Trimester Pregnancy: Extra Amniotic Foley's Catheter Balloon with Traction versus Combined use of Foley's Catheter Balloon and Extra Amniotic Instillation of PGF2 alpha. Gomal J Med Sci. 2013;11(1):92-96.

18. Wong KS, Ngai CSW, Yeo ELK, Tang LCH, Ho PC. A comparison of two regimens of intravaginal misoprostol for termination of second trimester pregnancy: a randomized comparative trial. Hum Reprod. 2000;15(3):709-12.

How to cite this article: Kusumam V.N, Khan N.B.A, Sruthi. V.G. Comparison of effectiveness of mifepristone misoprostol combination versus mifepristone Foley EAS (Extra-amniotic instillation of saline) combination in second trimester pregnancy termination. Indian J Obstet Gynecol Res. 2018;5(4):530-534. 